\title{
Nietzsche e a sociofisiologia do eu*
}

\author{
Herman Siemens**
}

\begin{abstract}
Resumo: Este artigo examina as considerações de Nietzsche acerca das fontes sociais e históricas do eu como um contra-argumento à concepção liberal de indivíduo. Defendo que Nietzsche oferece não apenas uma crítica contundente à concepção associal e previamente individuada de pessoa, à qual se conecta a noção liberal de liberdade (compreendida como o direito individual de escolha de sua própria concepção de bem), como ainda um contra-conceito alternativo de pessoa e de soberania. Seus argumentos visam mostrar, em sua dimensão crítica, que o indivíduo ou pessoa é inseparável de seus objetivos ou valores, que são socialmente constituídos, e que nossa capacidade como indivíduos, especialmente para a agência soberana, é o produto de uma longa história e pré-história social. Em sua dimensão construtiva, encontramos em Nietzsche a contra alegação de que a manutenção e o cultivo de nossas capacidades (para reflexão e agência soberanas) são dependentes de relações de um antagonismo ponderado entre nós mesmos enquanto indivíduos, ou antes: como dividua. Esses argumentos serão desenvolvidos no que se segue em consonância com quatro principais linhas de pensamento: sobre as origens sociais e o caráter da (auto) consciência (§I); sobre a (pré) história e a constituição social de
\end{abstract}

\footnotetext{
* Uma versão em inglês desse artigo foi publicada em SIEMENS, H. W. 'Nietzsche's SocioPhysiology of the Self', in: CONSTÂNCIO, J. BRANCO, M. \& Ryan, B. (eds.). Nietzsche and the Problem of Subjectivity. de Gruyter, 2015, pp. 629-653.Esse artigo tem por base um trabalho sobre as implicações políticas do pensamento de Nietzsche, especialmente sua crítica dos valores democrático-liberais (Siemens 2006, Siemens 2009a), bem como meu artigo Empfindung para a Nietzsche-Wörterbuch (NO 2011). Eu gostaria de agradecer a João Constâncio pela oportunidade de apresentar e debater uma versão anterior desse artigo em um workshop em Lisboa. Tradução de Daniel Temp. Revisão Técnica de Rogério Lopes.

** Professor Associado da Leiden University, Holanda. Professor Adjunto da UDP, Chile.

Correio eletrônico: hwsiemens@hotmail.com
}

Cad. Nietzsche, Guarulhos/Porto Seguro, v.37, n.1, p. 185-218, 2016. $\mid 185$ 
Siemens, H.

nossa capacidade como indivíduos soberanos [sovereign] (§II); sobre as origens sociais do fenômeno moral (como internalização de normas comuns) (§III); e sobre a destruição fisiológica do sujeito moral substancial, seguida da reconstrução fisiológica (§IV).

Palavras-chave: soberania - sociofisiologia - natureza - moral

\section{Introdução}

O que está em discussão neste artigo é a noção de indivíduo ou pessoa tal como ela é geralmente pressuposta pela teoria liberal do contrato, e mais especificamente por John Rawls, na assim chamada "posição original", formulada em seu célebre Uma Teoria da Justiça ${ }^{1}$. Irei examinar a tese de Nietzsche sobre as fontes sociais e históricas do eu - uma área do seu pensamento que não recebeu suficiente atenção - e reconstruí-la como um contra-argumento à concepção liberal de indivíduo. Mais especificamente, exponho esta tese em contraste com duas conhecidas acusações endereçadas a Rawls por seus críticos. Essas acusações afirmam que a noção de indivíduo formulada na posição original pressupõe que:

1. uma pessoa é previamente individuada: uma pessoa é o que ela é como pessoa independentemente dos fins ou valores que ela escolhe livremente; os fins que eu escolho não são constitutivos da minha identidade ou de quem eu sou.

2. a pessoa é associal: os fins de uma pessoa são formados antes ou independentemente da sociedade; a sociedade não fornece a identidade, valores ou fins de uma pessoa, mas ela é antes o resultado de um contrato entre os indivíduos cujos fins são previamente dados.

A validade dessas acusações, como críticas a Rawls, tem sido objeto de muita discussão ${ }^{2}$, mas para meu propósito isso é de

1 RAWLS, John. A Theory of Justice. Oxford: OUP, 1971, esp. §§ 4 e 24. Minha compreensão da noção de eu de Rawls e da oposição de Nietzsche a ela deve muito à explicação de David Owen em OWEN, David. Nietzsche, Politics \& Modernity. London: Sage, 1995, p. 133-138.

2 Para uma explicação do debate e uma avaliação crítica dessas posições, ver MULHALL, Stephen \& SWIFT, Adam. Liberals and Communitarians. Oxford: Blackwell, 1992 e MULHALL, Stephen

186 | Cad. Nietzsche, Guarulhos/Porto Seguro, v.37, n.1, p. 185-218, 2016. 
importância secundária. Em primeiro lugar, essas noções têm uma longa história no pensamento político e moral, especialmente em concepções como as do liberalismo democrático, nas teorias do contrato e da moralidade com as quais Nietzsche estava familiarizado, como veremos. Em segundo lugar, essas noções seguem conformando nossa autocompreensão cotidiana e pré-filosófica de agentes morais e políticos. E o que é mais significativo, elas são frequentemente atribuídas ao próprio Nietzsche por aqueles que o veem como um defensor do individualismo autárquico ou aristocrático. Esses são os principais alvos do contra-argumento nietzschiano dirigido ao conceito liberal de indivíduo que pretendo apresentar neste artigo.

O contra-argumento nietzschiano é tanto crítico quanto construtivo. Nietzsche formula não apenas uma forte crítica do conceito de pessoa [personhood] associal e previamente individuada, como também uma concepção alternativa e positiva de pessoa [personhood]. Seus argumentos visam mostrar, por um lado, que o indivíduo ou pessoa é inseparável de seus objetivos ou valores, que são socialmente constituídos, e que nossa capacidade como indivíduos, especialmente para a agência soberana, é o produto de uma longa história e pré-história social. Por outro lado, encontramos em Nietzsche a contra-alegação construtiva de que a manutenção e o cultivo de nossas capacidades (para reflexão e agência soberanas) são dependentes de relações de um antagonismo ponderado entre nós mesmos enquanto indivíduos, ou antes: como dividua. Esses argumentos serão desenvolvidos no que se segue em consonância com quatro principais linhas de pensamento:

\& SWIFT. "Rawls and Communitarianism". In. FREEMAN, S. (Ed.). The Cambridge Companion to Rawls. Cambridge: CUP, 2003, p. 460-487. Após Theory of Justice, a posição de Rawls leva em conta essas críticas. Para a última posição de Rawls, OWEN, David. Nietzsche, Politics \& Modernity, op. cit., p. 154-164, MULHALL, Stephen \& SWIFT. "Rawls and Communitarianism", op. cit. e MOUFFE, Chantal. "Democracy, Power and the "Political"". In. BENHABIB, Seyla (Ed.).Democracy and Difference: Contesting the boundaries of the political. Princeton: Princeton University Press, 1996, p. 245-256. 
Siemens, H.

I. sobre as origens sociais e o caráter da (auto) consciência;

II. sobre a (pré) história e a constituição social de nossa capacidade como indivíduos soberanos (sovereign);

III. sobre as origens sociais do fenômeno moral (como internalização de normas comuns); e

IV. sobre a destruição fisiológica do sujeito moral substancial, seguida da reconstrução fisiológica do sujeito como dividuum.

A maior parte dos textos que serão examinados aqui pertence ao Nachlass de 1880 - 1882 (KSA 9), especialmente as anotações 11 (= M III I de 1881), e estão situadas a nível fisiológico, como meu título indica. Discutir assuntos morais e políticos em termos fisiológicos é um "erro categorial" tipicamente nietzschiano, e é importante entender as razões que levam o filósofo a fazer isso. Um impulso central no pensamento de Nietzsche, do início ao fim, consiste em solapar a autonomia da esfera normativa e dissolver a autocompreensão da moralidade, enquanto instância soberana, em um plano de pensamento imanente, através do que ele denomina "naturalização da moralidade"3 ou "naturalismo moral" [moralistic naturalism]:

Eu posso designar a tendência dessas considerações como naturalismo moral: minha tarefa é traduzir os valores morais que aparentemente se tornaram emancipados e livres da natureza, de volta à sua natureza - i.e., à sua natural "imoralidade" (Nachlass/ FP 9 [86], KSA 12.3804. A naturalização dos valores morais requer

3 Para "naturalização da moralidade“ cf. Nachlass/FP 9 [8], KSA 12.342: "An Stelle der moralischen Werthe lauter naturalistische Werthe. Vernatürlichung der Moral" [Em vez de valores morais, só valores naturalistas. Naturalização da moral]; Cf. também "naturalismo moral" em Nachlass/FP 15 [5], KSA 13.403: "Kritik der Philosophie.[...] Die Philosophen als Moralisten: sie untergraben den Naturalismus der Moral" [Crítica da filosofia. [...] Os filósofos como moralistas: minam o naturalismo da moral].

4. "Ich darf die Tendenz dieser Betrachtungen als moralistischen Naturalismus bezeichnen: meine Aufgabe ist, die scheinbar emancipirten und naturlos gewordenen Moralwerthe in ihre Natur zurückzuübersetzen — d.h. in ihre natürliche "Immoralität" [Eu me permito designar a tendência dessas considerações como naturalismo moralista: minha tarefa é retraduzir os

188 Cad. Nietzsche, Guarulhos/Porto Seguro, v.37, n.1, p. 185-218, 2016. 
claramente uma compreensão naturalizada do ser humano, tarefa descrita em no parágrafo 230 de Para além de bem e mal, numa fórmula que se tornou célebre como a tarefa de "retraduzir o homem de volta à natureza" e de expor "o terrível texto básico homo natura" (JGB/BM 230, KSA 5.167). Essas tarefas não podem, contudo, ser enfrentadas diretamente, uma vez que o problema básico é que nosso conceito de natureza, especialmente o de natureza humana, foi inteiramente moralizado. Na visão de Nietzsche, a "idealização" ou "desnaturalização" [Entnatürlichung] da moralidade vem de mãos dadas com a moralização da natureza ${ }^{5}$. Traduzir a moralidade e o ser humano de volta à natureza é inútil se isso significa traduzi-los de volta a uma natureza moralizada. Esse é o motivo pelo qual Nietzsche escreve sobre a "natural imoralidade" de nossos valores (Nachlass/ FP 9 [86], KSA 12.380) e "o terrível texto básico homo natura" (JGB/BM 230, KSA 5.167): a natureza em questão é uma natureza que foi destituída de sentido moral e restituída à sua inocência e ferocidade. Estes são, portanto, dois movimentos que devem ser coordenados no projeto de naturalizar a moralidade: traduzir os valores e o ser humano de volta à natureza, e traduzir a moralidade a partir da natureza (humana): a Vernatürlichung der Moral [Naturalização da moral] vem de mãos dadas com a Entmoralisierung der Natur [a destituição do sentido moral da natureza] $]^{6}$. No texto que se segue

valores morais, aparentemente emancipados da natureza e tornados não naturais, de volta à sua natureza - ou seja, à sua "imoralidade" natural].

5 Em Nachlass/FP 9 [86], KSA 12.380, lemos: “[...] dem souverain gemachten Sittengesetz, losgelöst von seiner Natur ( - bis zum Gegensatz zur Natur - ) / Schritte der "Entnatürlichung der Moral" (sog. "Idealisirung")" [a lei moral feita soberana (- até converter-se no oposto da natureza -) / Passos da "desnaturalização da moral” (A chamada idealização)]. Nietzsche planeja aqui reconstruir esse processo de desnaturalização, passo a passo.

6 Para "Entmoralisierung", cf. Nachlass/FP 24 [7], KSA 10.646: "unser Bedürfniß ist jetzt die Welt zu entmoralisiren: sonst könnte man nicht mehr leben [...]" [O que precisamos agora é destituir o mundo de seu sentido moral: do contrário não conseguimos mais viver]. Cf. também Nachlass/FP 16[16], KSA 13.487: “Wir Wenigen oder Vielen, die wir wieder in einer entmoralisirten Welt zu leben wagen, wir Heiden dem Glauben nach [...]" [Nós, poucos ou muitos, que nos atrevemos a viver de novo em um mundo destituído de sentido moral, nós pagãos segundo a fé]; e como parte 
Siemens, H.

veremos exemplos de ambos.

\section{Sobre as origens sociais e o caráter da (auto) consciência}

Inicio apresentando um esboço da visão de Nietzsche sobre as origens sociais e o caráter social da (auto) consciência, assim como dos tipos de problemas que decorrem disso. Para tanto, tomarei como base dois famosos textos: "Do "Gênio da espécie"” (FW/GC 354, KSA 3.590) e "O que é afinal a vulgaridade?" (JGB/BM 268, KSA 5.221). Ambos os textos são reformulações polêmicas ou deflações da doutrina de Schopenhauer acerca do Genius der Gattung [Gênio da espécie], o qual guiaria a seleção de parceiros sexuais, sem conhecimento dos mesmos, para atender à finalidade do Gattung [espécie] de reproduzir os melhores espécimes (WWV II \$44). Em ambos os textos o argumento gira em torno da história e do desenvolvimento da linguagem. Em $A$ gaia ciência 354, Nietzsche argumenta que o desenvolvimento da (auto) consciência está ligado a necessidades comunicativas, isto é, ao valor seletivo ou de sobrevivência da habilidade de comunicação por parte de animais humanos. Linguagem, consciência e pensamento consciente dizem respeito, portanto, a necessidades compartilhadas e a interesses comuns sobrepostos - aos interesses do grupo ou rebanho, e não ao que é distintivo, diferente ou único a cada indivíduo. Desse

do plano de um livro, Nachlass/FP 10 [57], KSA 12.485: "Geschichte der Vermoralisirung und Entmoralisirung" [História da moralização e da destituição de sentido moral]; cf. Nachlass/FP 12 [1], KSA 13.203. O termo "Entmenschung" (e "entmenschlichen") está intimamente associado a "Entmoralisirung", uma vez que a moralização da natureza é frequentemente concebida como um processo de antropomorfização (Cf. $F W / G C$ 109, KSA 3.467). Cf. Nachlass/FP 11 [211], KSA 9.525: "Meine Aufgabe: die Entmenschung der Natur und dann die Vernatürlichung des Menschen, nachdem er den reinen Begriff "Natur" gewonnen hat" [Minha tarefa: a desumanização da natureza e, portanto, a naturalização do homem, depois de ele ter obtido o conceito puro de „,natureza“" Também cf. 11 [238], KSA 9.532: "Die Menschen und die Philosophen haben früher in die Natur hinein den Menschen gedichtet - entmenschlichen wir die Natur!" ["Os homens e os filósofos imiscuíram precocemente o homem na natureza - desumanizemos a natureza!'].

$190 \mid$ Cad. Nietzsche, Guarulhos/Porto Seguro, v.37, n.1, p. 185-218, 2016. 
modo, (auto) consciência não pode ser consciência do que é único ou distintivo em cada um de nós; ela não toma a perspectiva particular dos indivíduos, mas sim a perspectiva do rebanho, confinada aos interesses comuns sobrepostos; ela é um tipo de consciência coletiva individuada.

Este argumento faz parte da crítica mais ampla de Nietzsche à consciência em favor do corpo, este entendido como corpo social: incorporado em relações sociais, formado por elas e governado pelo mesmo tipo de "razão" que governa as interações sociais. Nós veremos mais sobre isso nos $§ \S$ II-IV. Mas já podemos ver que esse argumento milita contra o conceito liberal de indivíduo pré- ou associal. Pois no que concerne às origens sociais e à função da (auto) consciência a implicação do argumento é que nós somos indivíduos (auto) conscientes apenas na medida em que somos indivíduos sociais.

Em Para além de bem e mal 268, Nietzsche retoma a discussão sobre as origens sociais da linguagem e suas consequências. Aqui o foco não é na consciência, mas nas necessidades comuns ou compartilhadas, com a tese de que a linguagem (palavras) significam sentimentos compartilhados ou agrupados [Empfindungen/ Empfindungs-Gruppen]; isto é: experiências interiores [Erlebnisse] e necessidades [Bedürfnisse] não-únicas. Nietzsche prossegue argumentando que as necessidades mais importantes e urgentes são as primeiras a encontrar expressão linguística e, como tais, elas acabam por definir nossos valores fundamentais [Rangordnung der Werthe, Gütertafel]. Mas se, tal como ele argumentou, nossas necessidades e experiências recorrentes e comuns são as mais urgentes e importantes, segue-se que o indivíduo (autoconsciente) promoverá os valores correspondentes a necessidades comuns e recorrentes, isto é, os valores fundamentais ou a tábua de valores da comunidade ou sociedade a qual ele pertence. Combinando ambos os textos nós podemos reconstruir o seguinte argumento: na medida em que a (auto) consciência individual é ela mesma um produto 
Siemens, H.

da linguagem $(F W / G C 354, \mathrm{KSA} 3.590)$, e visto que a linguagem significa as necessidades comuns ou compartilhadas que determinam os valores da comunidade (JGB/BM 268, KSA 5.221), segue-se que o indivíduo (auto) consciente é inseparável de seus valores, e mais especificamente, dos valores fundamentais da comunidade à qual ele pertence. Essa implicação milita claramente contra o conceito liberal de indivíduo como associal e previamente individuado. De acordo com esse argumento, uma pessoa não pode ser entendida independentemente de seus objetivos ou valores; eles são constitutivos da pessoa [personhood]. Esses valores fundamentais tampouco são escolhidos livremente; eles são valores sociais ou comunais que articulam as necessidades comuns da sociedade ou comunidade à qual o indivíduo pertence.

Em contrapartida, esses argumentos também levantam sérios problemas para a própria prática comunicativa de Nietzsche e para nosso engajamento na linguagem. Eles implicam que a linguagem, o pensamento e a consciência são inadequados para comunicar as particularidades das pessoas. Se a linguagem está confinada ao que é comum, como então falar de necessidades, sentimentos e pensamentos que não são comuns, ou seja, são outros [anders] e particulares? Que tipo de engajamento na linguagem permitiria que particularidades fossem pensadas e ditas? Em uma anotação dos Fragmentos póstumos que começa (primeiro parágrafo) com um uma versão sumária e compactada do argumento do parágrafo 268 de Para além de bem e mal, Nietzsche escreve:

Palavras são signos fonéticos para conceitos: mas conceitos são grupos mais ou menos estáveis de sensações [Empfindungen] recorrentes e conjugadas. Para entender os outros não é o bastante usar as mesmas palavras: deve-se utilizar também as mesmas palavras para as mesmas experiências interiores [innere Erlebnisse] - e deve-se tê-las em comum [...] Qual grupo de sensações fica em primeiro plano é o que determina as avaliações: mas as avaliações são consequências de nossas necessidades mais íntimas. - Isso é dito com vistas a explicar o porquê de ser tão difícil entender escritos como os meus:

192 | Cad. Nietzsche, Guarulhos/Porto Seguro, v.37, n.1, p. 185-218, 2016. 
as experiências interiores, avaliações e necessidades são outras [anderes] no meu caso. Por anos eu tenho tido relações sociais com pessoas e eu tenho levado a autonegação e a polidez tão longe a ponto de nunca falar de coisas que estão perto do meu coração. De fato, esse é praticamente o único modo em que eu tenho vivido com as pessoas. - (Nachlass/FP 34 [86], KSA 11.448).

Tendo como pano de fundo suas restrições teóricas da linguagem àquilo que temos em comum, Nietzsche descreve aqui seu próprio confinamento ao nível das necessidades [gemeinsame Bedürfnisse] e experiências comuns nas relações com outras pessoas ao longo dos anos. Isso faz com que seja difícil perceber como nós poderíamos entender as experiências interiores de Nietzsche em sua alteridade, e ainda mais difícil entender como ele poderia comunicá-las. Mas em Para além de bem e mal 268, há também uma sugestão de como ele procura comunicar a alteridade de suas próprias experiências e necessidades particulares:

Os homens mais semelhantes, mais costumeiros, estiveram e sempre estarão em vantagem; os mais seletos, mais sutis, mais raros, mais difíceis de compreender, esses ficam facilmente sós, em seu isolamento sucumbem aos reveses, e dificilmente se propagam. É preciso invocar prodigiosas forças contrárias, para fazer frente a esse natural, muitíssimo natural progressus in simile [progresso no semelhante], à evolução do homem rumo ao semelhante, ao costumeiro, mediano, gregário - rumo ao comum [Gemeine] (JGB/BM 268, KSA 5.221) ${ }^{7}$.

Para os "schwerer Verständlichen" [difíceis de compreender] como Nietzsche, a tarefa é "atravessar" a progressiva similitude das pessoas, mediada pela linguagem. Assim, talvez a chave sobre como pensar e dizer o que é particular, é "atravessar" diferentes discursos ou jogos de linguagem, "cruzar" [to cross-breed] diversos discursos

7 Nesta citação, em específico, foi utilizada a tradução de Paulo César de Souza (doravante PCS), com uma pequena alteração. (N. T.) 
Siemens, H.

em direção a um texto que "anularia" [to cross out] ou ao menos resistiria à regra da similitude que governa cada um. Se for assim, nós temos outra indicação para o "erro categorial" nietzschiano de discutir assuntos morais e políticos em termos fisiológicos, ao qual eu retorno agora.

\section{Sobre a (pré) história e a constituição social de nossas capacidades como indivíduos autônomos}

Nietzsche oferece uma explicação naturalista da constituição histórica e social de nossas capacidades como indivíduos soberanos (a segunda crítica do liberalismo; cf. Nachlass/FP 11 [82], KSA 9.509). Este texto começa com um modelo orgânico [organismic] de soberania, no qual nossas capacidades são concebidas como qualidades ou "funções" do organismo, sendo o organismo (seguindo Roux $)^{\mathbf{8}}$ caracterizado sobretudo por processos de organização interna e de autorregulação:

Um ser humano forte e livre sente as qualidades do organismo contra [gegen] tudo o mais.

1) Autorregulação: sob a forma de medo de toda interferência estrangeira, no ódio contra [gegen] os inimigos, moderação etc.

2) Abundante compensação (overcompensation): sob a forma da cobiça, prazer de apropriação, ânsia de poder

3) Assimilação de si mesmo: sob a forma de louvor e censura, fazer os outros dependentes de si com o astuto fim de decepcionar, aprender, habituar; comandar e incorporar [Einverleiben] julgamentos e experiências

4) secreção e excreção: sob a forma de desprezo, desgosto por qualidades que por si só não são mais úteis; comunicando [mittheilen] sua abundante benevolência

5) Poder metabólico: veneração temporária, admiração, tornar-se dependente,

8 Cf. MÜLLER-LAUTER, Wolfgang“'Der Organismus als innerer Kampf. Der Einfluss von Wilhelm Roux auf Fr. Nietzsche”. In. Über Werden und Wille zur Macht, Nietzsche-Interpretationen I Berlin/New York: Walter de Gruyter, 1999, p. 97-140.

194 Cad. Nietzsche, Guarulhos/Porto Seguro, v.37, n.1, p. 185-218, 2016. 
enquadrar-se, quase dispensar o exercício das outras funções orgânicas, transformando a si mesmo em um "órgão", ser capaz de servir

6) regeneração: sob a forma do impulso sexual, impulso pedagógico etc. (Nachlass/FP 11 [182], KSA 9.509).

No entanto, essas capacidades não podem ser pressupostas como algo intrínseco aos seres humanos, como acontece nas teorias contratualistas liberais. Em vez disso, elas são o fruto tardio de uma longa história social que Nietzsche reconta. Ele o faz de uma perspectiva sociofisiológica na qual as origens sociais do indivíduo soberano não estão focadas em nossa razão (tal como enfatizado pelas teorias contratualistas liberais), mas sim em nossos afetos e impulsos [drives]. A tese é que os nossos impulsos não são "naturais", mas aprendidos e assimilados da sociedade ou estado.

Na primeira fase da história contada por Nietzsche, somos apenas órgãos de um organismo social maior que se autorregula e ao qual pertencemos ("sociedade"/“"o Estado"). Na segunda fase, indivíduos soberanos são formados quando os órgãos cessam de ser órgãos e tornam-se organismos autônomos (no lugar da sociedade ou Estado). Essa transição, segundo Nietzsche, é possível por meio de um processo de aprendizagem, assimilação e incorporação [Einverleibung]. Na primeira fase, quando seres humanos são órgãos, suas ações e impulsos são determinados pelas necessidades do organismo ao qual pertencem: eles sentem afetos da sociedade em relação a [gegen] outras sociedades e seres singulares [...] e não na qualidade de indivíduos; há somente inimigos públicos. Mas como um órgão, seres humanos assimilam também os interesses, as necessidades, as "experiências e julgamentos" do organismo, de modo que mais tarde, "quando os laços da sociedade se rompem", é possível reorganizar a si mesmo como um indivíduo autônomo ou organismo. Nietzsche fala da "reorganização e da assimilação e excreção de impulsos" como necessária para transformar um ser humano de órgão em organismo. 
Siemens, H.

Em uma passagem central da anotação, Nietzsche discorda dos pressupostos liberais em três considerações:

[1.] Primeiro a sociedade educa o ente singular [das Einzelwesen], o préforma em meio - ou indivíduo inteiro -; ela não é formada de entes singulares, nem do contrato entre eles! Ao contrário, o indivíduo é necessário ao menos como ponto focal (um guia), e este somente será livre em relação à posição mais ou menos elevada dos outros. Assim: [2.] o estado não é, em suas origens, algo que oprime os indivíduos: estes nem sequer existem! [3.] Ele [o estado] é que faz com que seja possível aos seres humanos existirem como animais de rebanho. Nossos impulsos e afetos nos são primeiramente ensinados lá: não há nada original neles! Não há “estado de natureza" para eles! Como partes de um todo, nós tomamos parte nas condições da existência e funções do todo, e incorporamos [einverleiben uns] as experiências e julgamentos feitos nesse processo (Nachlass/FP 11 [182], KSA 9.511).

As críticas de Nietzsche à teoria contratualista liberal são, portanto:

1. A sociedade não é formada através de um contrato entre indivíduos preexistentes; mas é a própria sociedade que educa e forma indivíduos, de modo que eles são produto da sociedade.

2. Uma vez que os indivíduos são produto da sociedade ou estado ao qual eles pertencem, o estado não pode ser entendido como uma ameaça aos indivíduos preexistentes. Em particular, o conceito liberal de liberdade individual como um poder primordial ou "direito natural" dos indivíduos que carecem de proteção contra o constructo artificial do estado é descartado.

3. A sociofisiologia de Nietzsche impossibilita que nossa capacidade racional seja abstraída de nossa existência incorporada, afetiva. Não apenas nossas "experiências e julgamentos" são incorporados e aprendidos do estado, mas também nossos afetos e impulsos. Juntos, eles são pré-formados pelos interesses e funções do organismo social ao qual pertencem originalmente. Isso descarta não apenas as teorias contratualistas liberais que pressupõem nossa

$196 \mid$ Cad. Nietzsche, Guarulhos/Porto Seguro, v.37, n.1, p. 185-218, 2016. 
capacidade racional ou reflexão autônoma (p.ex. Rawls), como também aquelas que pressupõem afetos e impulsos primordiais por parte do indivíduo, tais como o medo da morte e o desejo de autopreservação de Hobbes 9 .

Tudo isso implica claramente uma crítica da noção liberal de liberdade como o direito de escolher o conceito de bem, direito este associado a uma pessoa concebida como associal e previamente individuada. Mas isso levanta a seguinte questão: que sentido de liberdade individual ou soberania a sociofisiologia de Nietzsche deixa em aberto? Que Nietzsche deseja promover uma alternativa viável ao conceito liberal de liberdade fica claro a partir do modelo orgânico de soberania que inicia o texto. Um exame completo dessa explicação da soberania vai além do escopo desse artigo. Não obstante, a sociofisiologia de Nietzsche, neste e em outros textos, fornece alguns importantes indícios, sob a forma de condições necessárias, para a agência individual soberana. São eles 1. que a soberania exige um ethos radicalmente individual de autolegislação; e 2. que a soberania requer a maximização do antagonismo ou luta entre os impulsos ou poderes constitutivos do indivíduo. $\mathrm{O}$ segundo ponto estará localizado no contexto da reconstrução fisiológica nietzschiana do indivíduo como dividuum no $§$ IV. No momento, concentrar-me-ei no primeiro ponto, que surge quase como uma ideia adicional na explicação de Nietzsche da emergência do indivíduo a partir do organismo social.

Nesta segunda fase da narrativa de Nietzsche, "quando os laços da sociedade se rompem", os primeiros indivíduos experimentais, ou "Versuchs-Individuen", afirmam a si mesmos como soberanos. Esse processo envolve a transformação de um órgão em um organismo autônomo, uma dolorosa e difícil "reorganização, assimilação e

9 Cf. o parágrafo final de Leviathan Ch. XIII (HOBBES, Thomas. Leviathan. Oxford: Oxford University Press, 1998). No texto de Nietzsche, a guerra de todos contra todos de Hobbes é reconstruída como a fase na qual os indivíduos sofrem as disfunções que acompanham o rompimento do organismo social, devendo então assegurar sua própria existência como organismos individuais (e não apenas como órgãos) através da reordenação de seus impulsos e funções. 
Siemens, H.

excreção de impulsos":

Os tempos em que eles emergem são aqueles de desfazimento da eticidade dos costumes [Entsittlichung], da assim chamada corrupção, isto é, todos os impulsos agora querem seguir sozinhos, e uma vez que eles até agora não se adaptaram à utilidade pessoal [i.e., aos interesses vitais do indivíduo - HS], eles destroem o indivíduo através do excesso [Übermaaß]. Ou eles o dilaceram em sua luta [Kampfe] recíproca (Nachlass/FP 11 [182] KSA 9.511).

O conflito destrutivo dos impulsos, desencadeado por sua emancipação da dependência do organismo social, levou os primeiros filósofos morais a tentar resguardar o indivíduo mediante a recomendação de uma volta reacionária para a sujeição:

Os moralistas [Ethiker] tomaram a frente e procuraram mostrar aos seres humanos como eles ainda poderiam viver sem sofrer consigo mesmos - na maioria das vezes recomendando a eles o velho e condicionado modo de vida sob o jugo da sociedade, mas com a única diferença de que no lugar da sociedade comparece [o jugo] a um conceito - eles são reacionários. Mas eles preservam muitos, ainda que o façam ao preço de um retorno à servidão [Gebundheit]. Sua reivindicação é que há uma lei moral eterna [ewiges Sittengesetz]; eles não querem reconhecer a lei individual [das individuelle Gesetz] e chamam o esforço para atingi-la de imoral e destrutivo (Nachlass/FP 11[182], KSA 9. 512).

O indivíduo é por este meio resguardado do sofrimento, mas o mesmo não ocorre com sua soberania. O ethos da autossubmissão ao conceito de lei moral permite ao indivíduo nascente impor medida e paz a seus impulsos, mas ele o faz à custa da sujeição e conformismo. Se a autossubmissão à lei moral, concebida como universal e eterna, é o caminho da sujeição, então o caminho para a soberania é uma forma de autolegislação que é radicalmente individual, o que Nietzsche chama nesse contexto "das individuelle Gesetz"10. Esse pensamento,

10 Sobre a autolegislação radicalmente individual, cf. GERHARDT, Volker. "Selbstbegründung.

198 Cad. Nietzsche, Guarulhos/Porto Seguro, v.37, n.1, p. 185-218, 2016. 
que aparece en passant na anotação acima, é central em outra anotação do mesmo caderno de notas, na qual Nietzsche se ocupa da relação do indivíduo para com a espécie como um todo:

Os objetivos do indivíduo necessariamente são os objetivos da espécie? Não. Moralidade individual: como consequência de um lançar de dados ao acaso, há um ser aí que busca suas condições de existência - vamos levar isso a sério e não ser tolos que fazem sacrifícios para o desconhecido! (Nachlass/FP 11 [46], KSA 9.458).

Aqui Nietzsche nos adverte contra a autossubmissão - ou sacrifício pelo desconhecido - tal como a "lei moral eterna" - em favor de uma moralidade radicalmente individual. $\mathrm{O}$ que importa é o raciocínio naturalista por trás dessa posição: o clamor por uma moralidade radicalmente individual está fundado em um conceito naturalista de valor - como os meios para que uma dada forma-devida satisfaça suas condições de existência ${ }^{11}$, e na pressuposição de uma originária pluralidade de formas-de-vida, cada qual única e sujeita às suas próprias condições de existência. Cada um de nós é, como Nietzsche escreveu em Schopenhauer como educador, "ein Unicum", um "seltsamer Zufall", um "wunderlich buntes Mancherlei", misturados numa "Einerlei" cuja tarefa é "nach eignem Maass und Gesetz zu leben” (SE/Co. Ext. III 1, KSA 1.337) ${ }^{\mathbf{1 2}}$. Quando comparada com essas expressões da juventude, a nota de 1881 do Fragmento póstumo desloca a metafísica romântica das

Nietzsche's Moral der Individualität”. In. Nietzsche-Studien, 21, 1992, p. 28-49. Também SIEMENS, H. W. "Nietzsche and the Temporality of self-Legislation". In. DRIES, Manuel. Nietzsche on Time and History, (Ed.). Berlin /NY: de Gruyter, 2008, p. 191-210. SIEMENS, H. W. "Nietzsche's Critique of Democracy". In. Journal of Nietzsche Studies 38, Fall, 2009, p. 20-37.

11 Cf. Nachlass/FP 11[118] KSA 13.56; 14 [158], KSA 13.343. Em Para além de bem e mal, Nietzsche remete o conceito de valor à demandas fisiológicas de preservação por parte de uma forma-de-vida específica (JGB/BM 3, KSA 5.17).

12 "um único", um "raro acaso", "uma multiplicidade milagrosamente reunida", misturadas numa "unicidade" cuja tarefa é "viver conforme uma medida e uma lei". 
Siemens, H.

Considerações extemporâneas para um naturalismo (pós) darwiniano focado nas condições da existência ou da vida [Existenzbedingungen, Lebensbedingungen]. Dessa maneira, essa anotação ilustra como o "erro categorial" de discutir moralidade em termos fisiológicos pode servir a Nietzsche como uma estratégia textual para atravessar [crossing-out], ou pelo menos resistir, à regra de similitude da linguagem, assim como para falar de uma perspectiva particular: a particularidade, como o fundamento da demanda por uma moral radicalmente individual, é ela mesma fundada nas condições de existência específicas de cada forma-de-vida única. Ao mesmo tempo, essa nota também lança luz sobre o conceito orgânico de soberania proposto por Nietzsche (Nachlass/FP 11 [182], KSA 9.511; ver citação acima) como um modelo para a agência social individual. A soberania nietzschiana é não-soberana no sentido de que ela depende do cultivo de certas relações com os outros; ela está profundamente enraizada e é inteiramente relacional por definição. Mas ela é soberana no sentido de que essas relações são determinadas de dentro por uma forma-de-vida específica ("organismo") na procura das melhores condições de existência que são únicas para ela, e pelo tipo de autorregulação que isso requer. A virada de Nietzsche rumo à fisiologia, ou a virada fisiológica na explicação de Nietzsche da soberania, permite a ele, portanto, repensar a autodeterminação em termos relacionais e radicalmente individuais: a soberania requer que um indivíduo determine suas ações em relação aos outros em resposta àquelas condições que permitem a ele satisfazer de forma optimal suas necessidades e florescer como uma forma-de-vida única.

Permanece obscuro, no entanto, se a soberania nesse sentido é possível ou se ela é somente um ideal moral naturalista. Na anotação em questão, ela é atribuída aos "seres humanos livre e fortes" [starker freier Mensch] que são postos no fim da narrativa sociofisiológica de Nietzsche como "os seres humanos que se tornaram livres" [freigewordener Mensch]. Contudo, nas últimas linhas ele fala de 
nós [wir] como seres deformados [Mißgestalten] e de nosso mal-estar [Mißßbehagen] como "indivíduos no processo de se tornarem livres [frei werdenden Individuen]" (Cf. Nachlass/FP 11 [182], KSA 9.512). Se a autossubmissão à lei moral eterna, como recomendado pelos filósofos morais, é o caminho da servidão, como pode a liberdade individual radical ser de todo concretizada? Como pode o indivíduo ser resguardado do conflito destrutivo dos impulsos de modo alcançar a soberania? Retomaremos essas questões no $\S$ IV.

\section{Sobre as origens sociais dos sentimentos morais}

Como parte do projeto de naturalização da moralidade, a sociofisiologia de Nietzsche traduz o ser humano de volta à natureza de modo a minar a noção liberal de liberdade entendida como o direito de escolha por parte de uma pessoa associal e previamente individuada. Mas como vimos na introdução, a natureza e a natureza humana em particular foram completamente moralizadas ao longo da história da moralidade, e devem ser destituídas de sentido moral [de-moralised] a fim de que a naturalização da moral faça sentido. Nesta seção retorno a uma série de textos em que Nietzsche busca destituir a natureza humana de sentido moral [de-moralise] e recuperar sua inocência, argumentando que nossos sentimentos morais não são naturais, mas consequência da internalização de normas sociais. Ao enfatizar as origens sociais de nossos fins e valores morais, esses textos solapam a afirmação liberal de que a pessoa [personhood] é separada dos fins e valores escolhidos de forma livre e independentemente da sociedade.

Em um desses textos, Nietzsche contesta a noção de consciência [das Gewissen] como uma norma interna à qual poderíamos recorrer como um padrão privilegiado [gold standard] para avaliar ações e opiniões. Essa contestação se dá primeiramente pela redução da consciência a um conjunto de sentimentos morais [Empfindungen], e 
Siemens, H.

em seguida pela redução destes sentimentos a meros sentimentos de inclinação ou aversão [ $Z u$ - und Abneigung] que teriam sido imitados [nachgeamt] daqueles que têm autoridade moral sobre nós:

Que os humanos têm dentro de si mesmos a norma de acordo com a qual eles têm de agir - ainda se crê nessa extraordinária estupidez hoje em dia! Consciência! Ela é a soma de sentimentos de inclinação e aversão em relação a ações e opiniões, sentimentos imitados com que os quais nos deparamos nos pais e professores! (Nachlass/FP 5 [13], KSA 9.103).

A redução naturalista da voz interior da consciência a um conjunto de sentimentos imitados [Summe nachgeahmte Empfindungen] de inclinação/aversão a priva claramente de sua inquestionável autoridade normativa. Mas o efetivo mecanismo de imitação ou internalização, tal como Nietzsche o descreve, tem também o efeito de livrar a natureza humana de quaisquer qualidades ou sentimentos morais. Isso pode ser visto em uma anotação na qual Nietzsche examina o juízo acerca de "uma ação má" em termos sociofisiológicos:

Em si mesmos os impulsos não são nem bons nem maus para nossos sentimentos. [...] Quando a satisfação de um impulso é sempre acompanhada de um sentimento de proibição e aflição, cresce uma aversão contra ele: nós agora o consideramos mal. Nós o ligamos a um sentimento que o acompanha inseparavelmente, uma nova unidade surge. "Uma ação má" (Nachlass/FP 6 [204], KSA 9.251).

O que está em questão nesta passagem são nossos julgamentos morais negativos no que toca aos nossos próprios impulsos. A noção de "uma ação má" é remetida de volta à sua vinculação com um dado impulso, ou melhor: sua satisfação é acompanhada de um sentimento de aversão. Mas como acontece de um sentimento de aversão se ligar à satisfação de um impulso? A ideia de que isso possa ser o resultado de sentimentos morais internos que se relacionam com nossos impulsos 
é descartada em favor de um processo de socialização: a aversão para com a satisfação de um impulso é sentida na medida em que uma proibição social é internalizada na forma de um "sentimento de proibição e aflição" que acompanha sua satisfação. Como Nietzsche escreve em outra anotação: "Ter um impulso e sentir repugnância com sua satisfação é o fenômeno "moral"'13. A moralização de nossos impulsos através do processo da internalização é mais bem descrita em uma anotação na qual o caráter social ou relacional de nossos impulsos é claramente enunciado:

Que impulsos poderíamos ter que não nos colocassem desde o começo em uma determinada disposição em relação aos outros: nutrição, impulso sexual? Aquilo que os outros nos ensinam, o que querem de nós, que nos dizem para temer ou perseguir, constitui a matéria original de nossa mente: julgamentos alheios sobre as coisas. Eles nos dão nossa imagem de nós mesmos, de acordo com a qual medimos a nós mesmos, bem - ou mal satisfeitos conosco mesmos! Nosso próprio julgamento é somente a extensão [Fortzeugung] de [julgamentos] alheios combinados! Nossos próprios impulsos aparecem a nós sob a interpretação de outros: embora no fundo eles sejam todos agradáveis [angenehm], eles estão tão misturados com sentimentos desagradáveis que os acompanham [unangenehmen Beigefiihlen] através de julgamentos inculcados a respeito de seu valor, que de fato alguns são agora sentidos como maus impulsos: "eles me levam onde eu não deveria [nicht sollte] ir" - quando na verdade um impulso mau é uma contradictio in adjeto (Nachlass/FP 6 [70], KSA 9.212).

Em si mesmos nossos impulsos não são bons nem maus. Em si mesmos, eles sequer são sentidos [empfunden] por nós como sendo bons ou maus. Em vez disso, quando julgamos um impulso como mau, é apenas porque o prazer de sua satisfação está misturado com desprazer ou aversão. E nós sentimos desprazer com a satisfação de um impulso como resultado da internalização, em nosso meio

13 "Einen Trieb haben und vor seiner Befriedigung Abscheu empfinden ist das "sittliche" Phänomen" (Nachlass/FP 6 [365], KSA 9.290). [Ter um impulso e sentir timidez ante sua satisfação é o fenômeno "moral"] 
Siemens, H.

social, de interpretações, julgamentos ou proibições alheias. Essa consequência dessa explicação da moralização dos nossos impulsos é a destituição de seu sentido moral: o conceito de um impulso mau é contraditório, uma vez que a satisfação de um impulso não é boa nem má; em si mesma ela é simplesmente agradável [angenehm]. Mas essa explicação também mostra quão profundo é o processo de socialização para Nietzsche. Os argumentos a favor do caráter social da (auto) consciência individual extraídos da linguagem, expostos no $§$ I, são aqui reforçados em termos de uma internalização de interpretações e julgamentos morais alheios. Os julgamentos morais alheios não são apenas a fonte dos nossos julgamentos morais; eles são a matéria ou conteúdo original de nossa mente e fornecem nossa própria imagem e compreensão de nós mesmos. A distância que separa essa visão da visão do indivíduo associal e autointeressado, pressuposta nas teorias contratualistas liberais, é enunciada de forma clara e detalhada nessa mesma anotação, onde Nietzsche escreve:

Remeter todas as relações sociais ao egoísmo? Bem: mas para mim é também verdadeiro que todas as experiências interiores [innere Erlebnisse] egoístas devem ser remetidas às nossas habituadas e inculcadas disposições para com os outros (Nachlass/FP 6 [70], KSA 9.212).

Tanto o caráter internalizado e social do eu, quanto nossa relação conosco mesmos são centrais para a demolição crítica de um sujeito moral substancial empreendida por Nietzsche, bem como para sua tentativa de reconstruir o sujeito como dividuum, tema para o qual eu me volto agora.

\section{Contra o sujeito como uma substância unificada}

A crítica de uma ontologia substancial em favor de uma interpretação dinâmica e pluralista da realidade é um dos grandes 
temas que atravessam toda a obra de Nietzsche ${ }^{\mathbf{1 4}}$. Grande parte dessa crítica é dirigida ao conceito de sujeito, frequentemente visto como a fonte de nossa crença projetada em coisas estáveis ou mesmo em substâncias no nosso entorno. Nesse contexto, a crítica de uma ontologia substancial toma a forma de uma desconstrução fisiológica do sujeito moral substancial, seguida da reconstrução fisiológica do sujeito como dividuum. Dessa forma, o sujeito é pluralizado e dinamizado no conceito nietzschiano de um "sistema-de-vida" [life-system] ou organismo, e nossa crença em um sujeito moral substancial, nosso próprio "sentimento de subjetividade" [SubjektEmpfindung], é reduzido a "meios de preservação", "uma condição da vida para existência orgânica” (Nachlass/FP 11 [270], KSA 9.545). Mas Nietzsche procura também formular um contra-ideal prescritivo ao ideal liberal de autonomia subjetiva: uma explicação fisiológica, dinâmica e pluralista de soberania. Como argumentarei, o texto de Nietzsche sugere um ideal agonístico de uma pluralidade interior em um conflito moderado e fecundo, sustentado e entrelaçado com uma pluralidade exterior de seres soberanos ou organismos engajados em um conflito moderado e produtivo uns com os outros.

A crítica de Nietzsche a uma ontologia substancial acarreta a tarefa de explicar em termos naturalistas como nós viemos a tomar substâncias - a existência de coisas estáveis, incluindo o sujeito como sendo verdades fundamentais e autoevidentes. De modo geral, ele argumenta que essas "verdades" possuem valor seletivo ou de

14 Para um tratamento mais detalhado da crítica de Nietzsche a uma ontologia substancial, cf. AYDIN, Ciano. Zijn en Worden. Nietzsches omduiding van het substantiebegrip, Maastricht: Shaker, 2003. Na primeira fase de sua obra, Nietzsche registra a crítica de Schopenhauer, de 1868, focada no conceito de unidade e aponta que essa unidade é projetada do campo fenomênico para o campo noumênico. ( $Z$ u Schopenhauer, dated Oktober 1867 - April 1868, in: BAW III 352 - 370 (452 - 3 for Nachbericht). Cf. também Katrin Meyer sobre Nietzsche defender um ataque aos conceitos epistemológicos de ser, substância etc., nascido de seu engajamento da juventude com os pré-socráticos (MEYER, Katrin. Ästhetik der Historie: Fr. Nietzsches "Vom Nutzen und Nachteil der Historie für das Leben", Epistemata Würzburger Wissenschaftliche Schriften, Reihe Philosophie Bd. 238. Würzburg: Königshausen \& Neumann, 1998, p. 8-38). 
Siemens, H.

sobrevivência, isto é, possuem valor como meios de preservação da vida orgânica, mas nem por isso são verdades. Ele repete com insistência que o valor seletivo de uma crença é logicamente independente de seu valor de verdade. Assim:

É no modo como as primeiras formas [Bildungen] orgânicas sentiram estímulo e julgaram o exterior que o princípio de preservação da vida deve ser procurado: que crença prevaleceu, preservou a si mesma, através da qual a existência contínua se tornou possível; não a crença mais verdadeira, mas a mais útil. "Sujeito" é a condição para a existência da vida orgânica, por isso não a "verdade"; mais, a sensação de sujeito [Subjekt-Empfindung] pode ser essencialmente falsa, mas é o único meio de sobrevivência. $O$ erro é o pai dos seres vivos. [...] (Nachlass/FP 11 [270], KSA 9.545; cf. 11 [268], KSA 9.543).

"Sensação de sujeito" [Subjekt-Empfindung] não é uma verdade originária sobre a natureza humana, mas um erro secundário formado em resposta às condições de existência de toda vida orgânica. Essa mentira protoplasmática [protoplasmic] primordial vive em nossa crença política no estado como um todo estável, argumenta Nietzsche, pela mesma razão que todas as formas-de-vida orgânicas percebem "coisas estáveis" em seu entorno: para facilitar o processo de assimilação e subordinação:

Nas condições mais desenvolvidas nós ainda cometemos o erro mais primitivo: i.e., nós representamos o estado para nós mesmos como algo inteiro e estável, real como uma coisa, e consequentemente submetemo-nos a ele, como uma função [do mesmo]. Sem a representação protoplasmática de uma "coisa estável" fora de nós mesmos, não haveria submissão nem assimilação (Nachlass/FP 11 [270], KSA 9.545).

Em outros contextos, Nietzsche nos alerta contra a associação do pretenso "indivíduo" com o "sistema-de-vida" [life-system] que nós realmente somos: 
Mas eu distingo: os indivíduos imaginários e os "sistemas-de-vida" [Lebenssysteme] reais que cada um de nós somos - eles são confundidos, ao passo que "o indivíduo" é a soma de sentimentos conscientes [Empfindungen], julgamentos e erros, uma crença, uma pequena parte do sistema-de-vida real ou mesmo muitas pequenas partes concebidas juntas e associadas [zusammengedacht und zusammengefabelt], uma "unidade" que não se sustenta. [...] Aprender passo a passo a abandonar o pretenso indivíduo! Expor os erros do ego! Ver egoísmo como um erro! Mas não confundir altruísmo como seu oposto! Isso seria somente amor para com outro pretenso indivíduo! Não! Ir além do "eu" e "tu"! Sentir cosmicamente [Kosmisch empfinden]! (Nachlass/FP 11 [7], KSA 9.443).

Qualquer que seja o significado exato de "sentimento cósmico", ele acarreta um modo de relacionar-se consigo mesmo e com os outros para além das falsas unidades do "eu" e do "tu", e é parte do programa prescritivo de livrar-se de uma concepção equivocada de indivíduo anunciado nessa anotação. No contexto da crítica nietzschiana de uma ontologia substancial, isso envolve reescrever nossa relação conosco mesmos sem pressupor uma unidade ou identidade subjacente, partindo ao invés disso de uma multiplicidade originária. Desse modo, na anotação acima o sujeito moral substancial é descrito como uma falsa unidade que é de fato ficcionalizada [zusammengefabelt] a partir da multiplicidade de "sentimentos", "julgamentos", "erros" ou "partes" do sistema-de-vida [life-system] real. A tarefa prescritiva de Nietzsche é formular uma forma viável de relação consigo mesmo [self-relation] que não falsifique, mas que faça justiça ao que nós somos. Como nós esperaríamos a partir dos textos considerados no $§$ III, essa multiplicidade "interior" é formada através da internalização de costumes sociais. Uma vez que "wir haben die "Gesellschaft" in uns verlegt" ["Nós internalizamos a sociedade"], nós nos relacionamos conosco mesmos em termos completamente socializados:

Nós dirigimos todos os habituais impulsos bons e maus contra nós mesmos: pensando em nós mesmos, sentindo a favor e contra nós [Empfinden für und gegen uns] a luta que ocorre em nós - nunca nos consideramos indivíduos, 
Siemens, H.

mas sim dois ou uma multiplicidade; nós exercemos em nós mesmos todas as práticas sociais (amizade, vingança, inveja). O egoísmo ingênuo do animal foi completamente alterado por nossa integração social: nós já não podemos sentir a singularidade [Einzigkeit] do ego, nós estamos sempre entre muitos. Nós nos dividimos e continuamos a nos dividir mais vezes. Os impulsos sociais (como inimizade, inveja, ódio - os quais pressupõem uma pluralidade) nos transformaram: nós deslocamos a "sociedade" para dentro de nós mesmos, nós a comprimimos, e refugiar-se em si mesmo não é uma fuga da sociedade, mas frequentemente um desconfortante sonhar e interpretar dos processos que ocorrem em nós de acordo com o esquema das experiências anteriores [...] (Nachlass/FP 6 [80], KSA 9.215).

Mesmo no recuo para a solidão - muitas vezes tomado como um indicativo do individualismo autárquico de Nietzsche - nós praticamos relações sociais conosco mesmos, e trazemos conosco todos os nossos hábitos e impulsos sociais. Mas o que é notável nessa explicação não é tanto a redescrição de nossa relação conosco mesmos como uma internalização de relações sociais, mas sim a ênfase no conflito e na autodivisão ("a favor e contra"). Nessa anotação, é difícil compreender o teor exato - descritivo e/ou prescritivo - da afirmação. Mas em outras anotações o elemento prescritivo é inequívoco:

Qualquer um que seja capaz de sentimentos profundos deve também sofrer a veemente luta entre eles e seus opostos. A fim de ser perfeitamente tranquilo e sem sofrimento interior, alguém pode simplesmente se desacostumar dos sentimentos profundos, de modo que em sua fraqueza desperte somente fracas forças contrárias: eles podem então, em sua sublimada tenuidade, ser desentendidos e dar aos seres humanos a impressão de que estão em completa harmonia consigo mesmos... - Assim é na vida social: se tudo deve proceder altruisticamente, então as oposições entre indivíduos devem ser reduzidas a um mínimo sublime: de modo que todas as tensões e tendências hostis, através das quais o indivíduo mantém a si mesmo como indivíduo [durch welche das Individuum sich als Individuum erhält] mal são percebidas, o que quer dizer: os indivíduos devem ser reduzidos à mais delicada tonalidade da individualidade! Assim, a igualdade prevalece amplamente! Isso é eutanásia, é completamente infecundo! [...] (Nachlass/ FP 6[58], KSA 9.207)

208 Cad. Nietzsche, Guarulhos/Porto Seguro, v.37, n.1, p. 185-218, 2016. 
Nietzsche e a sociofisiologia do eu

De acordo com a hipótese (contra uma ontologia substancial) de uma pluralidade originária de sentimentos [Empfindungen] em conflito, não pode haver algo como uma paz genuína, harmonia ou acordo consigo mesmo. Alguém pode, no entanto, suspender o antagonismo entre seus sentimentos e interpretar isso como paz ou harmonia, através de estratégias que enfraquecem seus sentimentos e assim reduzem o veemente desacordo de seus antagonismos. Isso é uma clara referência ao ideal socrático de acordo consigo mesmo ${ }^{15}$ e à tendência eudaimonística que Sócrates introduz na filosofia ${ }^{16}$. É

15 Górgias 482c: "Me fora preferível [...] não concordar com minhas opiniões a maioria dos homens, e combatê-las, a ficar em desarmonia comigo mesmo e vir a contradizer-me" (PLATÃO. Górgias. Trad. de Carlos Alberto Nunes. Ed. Universitária do Pará, 2002, p. 180). Em "Philosophy and Politics", a versão de Hannah Arendt é: "seria muito melhor estar em desacordo com o mundo inteiro do que, sendo um, estar em desacordo comigo mesmo" (p. 87). Nesse artigo ela defende essa posição contra o espírito divisionista do agon na Grécia e ao mesmo tempo nega que a unidade ou harmonia consigo mesmo proposta por Sócrates exclua o pluralismo (ARENDT, Hannah. "Philosophy and Politics". In. Social Research 57/1 (Spring), 1990, p. 73-103). Segundo Nietzsche, como veremos, o desacordo ou alguma quantidade de conflito é necessária para o pluralismo genuíno.

16 Cf. Nachlass/FP 19[20], KSA 7.422: "Nach Sokrates ist das allgemeine Wohl nicht mehr zu retten, darum die individualisirende Ethik, die die Einzelnen retten will”.[„„Para Sócrates não era mais possível salvar o bem-estar geral. Isso explica sua ética individualizada, que visa à salvação do indivíduo"]. Mas em 1869 Nietzsche escreve: "Euripides hat von Socrates die Vereinzelung des Individuums gelernt" ["Eurípides aprendeu com Sócrates a singularização do indivíduo"] (Nachlass/FP 1 [106] KSA 7.41). Cf. também Nachlass/FP 23 [35], KSA 7.555: "Sokrates bricht mit der bisherigen Wissenschaft und Kultur, er will zurück zur alten Bürgertugend und zum Staate” [„Sócrates rompeu com a ciência e a cultura da época; ele pretendia um retorno à antiga virtude cívica e ao estado"]. Veja também as notas sobre "Wissenschaft und Weisheit und im Kampfe” [„Ciência e Sabedoria em conflito“]: Nachlass/FP 6 [13], KSA 8.102 "Von Sokrates an: das Individuum nahm sich zu wichtig mit einem Male" ["A partir de Sócrates: o indivíduo toma a si mesmo como demasiadamente importante, pela primeira vez"]; Nachlass/ FP 6 [15] KSA 8.103: sobre os filósofos pré-socráticos: "Bei ihnen hat man nicht "die garstige Pretension auf Glück", wie von Socrates ab. Es dreht sich doch nicht alles um den Zustand ihrer Seele: denn über den denkt man nicht ohne Gefahr nach” [„Entre os pré-socráticos não encontramos ,a mais desagradável pretensão à felicidade', como ocorre a partir de Sócrates. As coisas não giram em torno do estado de suas almas: pois sobre esse estado não é possível refletir sem risco"]; e igualmente Nachlass/FP 6 [15] KSA 8.103: "sie [die ältere Philosophie - HS] ist nicht so individuell-eudämonologisch, ohne die garstige Pretension auf Glück" [Ela [a filosofia arcaica HS] não é tão individual e eudaimonisticamente orientada, nela não se encontra a 
Siemens, H.

importante perceber que, de acordo com Nietzsche, essa estratégia para alcançar a harmonia ou paz interior aparece de mãos dadas com a estratégia de autossubmissão ao "conceito soberano"17 (a lei moral) atribuída aos primeiros filósofos morais [Ethiker] na sociofisiologia de Nietzsche (Nachlass/FP 11 [182], KSA 9.511), discutida no § II. Ambas as estratégias têm a vantagem de resguardar o indivíduo do sofrimento por meio da imposição de medida [Maass] sobre o excesso [Übermaas] dos impulsos individuais, assim como reduzir a tensão ou conflito entre eles (Nachlass/FP 11[182], KSA 9.511). Contudo, elas cobram um preço elevado. Na anotação acima Nietzsche escreveu sobre a perda da riqueza e da diversidade humanas em nome da uniformidade, bem como da perda do poder produtivo: uma morte em vida ou "eutanásia". No Fragmento póstumo 11 [182], como vimos, ele escreve sobre o conformismo e a servidão ao longo do caminho dos filósofos morais. Podemos agora tomar a questão em seu contexto: se a medida e a paz interior obtida através da autossujeição à lei moral eterna e universal é o caminho da servidão, como então pode a liberdade radicalmente individual ser de todo concretizada? Como o indivíduo pode ser resguardado do conflito destrutivo de seus impulsos de modo a que se promova sua soberania? A partir do texto acima fica claro que Nietzsche dá preferência ao veemente antagonismo de nossos impulsos, e não à sua redução a uma paz indiferente, como a chave para uma pluralidade de indivíduos vibrantes e fecundos. $\mathrm{O}$ mesmo pode ser dito de sua sociofisiologia, na qual Nietzsche formula um ideal prescritivo de soberania centrado no conflito. Em uma outra anotação relacionada à sociofisiologia, ele distingue nitidamente

desagradável pretensão à felicidade"]. Em Nachlass/FP 6 [26], KSA 8.108, ele acusa Sócrates de tirar o indivíduo para fora de seu contexto histórico e em Nachlass/FP 6 [21], KSA 8.106, ele caracteriza a posição de Sócrates com as palavras: "da bleibt mir nichts als ich mir selbst; Angst um sich selbst wird die Seele der Philosophie." [“ali nada mais resta senão eu comigo mesmo; o cuidado consigo mesmo se torna a alma da filosofia"].

17 Cf. Nachlass/FP 16 [17] KSA 7.399: "Socrates. Liebe und Bildung. Der souveräne Begriff" [„,Sócrates. Amor e Formação. O conceito soberano“].

$210 \mid$ Cad. Nietzsche, Guarulhos/Porto Seguro, v.37, n.1, p. 185-218, 2016. 
entre o caminho da servidão, inaugurado pelos primeiros filósofos morais, como a história do "animal de rebanho" que veio a dominar a modernidade, e a história de seres singulares solitários, como o caminho para a soberania: "O desenvolvimento de animais de rebanho e plantas sociais é inteiramente distinto daquele dos seres solitários ou singulares [einzeln lebend]) (Nachlass/FP 11 [128] KSA 9.488)".

No primeiro caso, Nietzsche enfatiza a predominância da autossubmissão [Unterordnung] atual (o estado, a família, a igreja etc.) e sua longa pré-história na nossa existência enquanto órgãos individuais prévios de um organismo social. No segundo caso, ele enfatiza o crescimento da complexidade do indivíduo através da incorporação de estruturas sociais, mas também as dificuldades da transição de órgão para um organismo autorregulador:

"Pessoas solitárias [Einzeln lebend], se elas não perecem, desenvolvem-se em sociedades, e uma série de âmbitos de atuação são desenvolvidos, e muita luta de impulsos para nutrição no espaço e no tempo também". (Nachlass/FP 11[128] KSA 9.488). Mas o conflito não é apenas uma característica do surgimento de indivíduos singulares; ele também é central para o ideal de soberania formulado no final desta anotação:

O homem mais livre é o que tem o maior sentimento de poder sobre si mesmo, o maior conhecimento sobre si mesmo, a maior ordenação no conflito necessário de seus poderes, a máxima independência relativa de seus poderes individuais, o maior conflito relativo dentro de si mesmo: ele é o ser mais discordante e o mais mutável, o que vive mais longamente e o que deseja e nutre a si mesmo de forma superabundante, aquele que em maior medida se aparta de si mesmo e em maior medida se renova (Nachlass/FP 11 [130], KSA 9.488).

Muitas das funções autorreguladoras do modelo orgânico de soberania proposto por Nietzsche (Nachlass/FP 11[182], KSA 9.511) podem ser identificadas nessa descrição: 
Siemens, H.

* “aquele que deseja de forma superabundante" refere-se a "2) Abundante compensação [overcompensation]: sob a forma da cobiça, prazer de apropriação, ânsia de poder";

* "aquele que [de forma superabundante] nutre a si mesmo" refere-se a "3) Assimilação de si mesmo: sob a forma de louvor e censura, fazer os outros dependentes de si com o astuto fim de decepcionar, aprender, habituar, comandando e incorporando [Einverleiben] julgamentos e experiências;"

* "aquele que em maior medida se aparta de si mesmo" referese a "4) secreção e excreção: sob a forma de desprezo, desgosto por qualidades que por si só não são mais úteis; comunicando [mittheilen] sua abundante benevolência";

* aquele que "renova" refere-se à "6) regeneração: sob a forma do impulso sexual, impulso pedagógico etc.

Todas essas funções classificam-se como a autorregulação ou a conquista da "suprema ordenação" e do "sentimento de poder" sobre si mesmo que disso resulta. Ordenação interior por meio de autorregulação efetiva é, portanto, a chave para o conceito de soberania proposto por Nietzsche. Mas como a anotação mostra claramente, a obtenção da ordenação interior é inseparável do que resiste à ordem: o antagonismo ou conflito entre forças. E assim como o veemente antagonismo de nossos sentimentos deve ser maximizado para que haja uma pluralidade de indivíduos vibrantes (Cf. Nachlass/ FP 6 [58], KSA 9.207), a grande soberania resulta da maximização do antagonismo entre forças e do sentimento de poder sobre si mesmo que provém da capacidade de ordená-las. Deste modo, podemos afirmar que soberania requer que sustentemos a tensão entre o máximo antagonismo e a máxima ordenação na pluralidade das forças ou impulsos que constituem cada um de nós.

Nietzsche pretende claramente que esse ideal apresente-se como um contra-ideal tanto à noção liberal de autonomia subjetiva quanto ao ideal socrático de paz interior ou acordo consigo mesmo, 
à lei moral e ao conformismo. A ontologia social dinâmica e plural na qual se funda o conceito de soberania de Nietzsche rompe com a metafísica substancial sobre a qual repousa a noção de pessoa associal e previamente individuada. Como argumentei no $\S$ II, a virada fisiológica no discurso de Nietzsche não apenas naturaliza, mas também singulariza o conceito de soberania, referindo-se à autodeterminação dos processos de autorregulação que melhor permitem a uma dada forma-de-vida encontrar as condições de existência únicas a ela enquanto ser singular. E como vimos no Fragmento póstumo 11[182], soberania, nesse sentido (como autolegislação radicalmente individual), se opõe especificamente à autossujeição ao conceito de uma lei moral eterna e universal, ao conformismo e à perda da diversidade humana que tudo isso implica. Finalmente, o ideal de maximização do antagonismo interior é visivelmente oposto ao ideal socrático de paz ou acordo consigo mesmo e ao enfraquecimento dos afetos sobre o qual ele repousa. A oposição de Nietzsche tanto ao ideal liberal quanto ao socrático depende em grande medida da tese de que não pode haver nem um pluralismo genuíno nem liberdade se não houver alguma medida para o conflito. Mas alguém poderia perguntar qual a medida certa de conflito e como ela é determinada. Qual é a medida para maximizar o antagonismo de nossos impulsos sem que o indivíduo como um todo se desintegre sob a pressão de impulsos desmedidos em conflito? De fato, como se pode encontrar a medida ou os limites para nossos impulsos, se o conflito entre eles deve ser maximizado?

Se o problema é como evitar a desintegração ou explosão do indivíduo sob a pressão (para fora) do conflito máximo dos seus impulsos, a solução pareceria envolver o exercício de pressões exteriores voltadas para dentro, pressões que nem subjugam ou consomem o indivíduo, nem são subjugadas por ele, mas que sejam mais ou menos iguais às pressões expansionistas exercidas para fora por seu poder. Em outras palavras, a medida para maximizar o 
Siemens, H.

antagonismo interior que seja compatível com a unidade do indivíduo é dada por relações sociais, intersubjetivas ou políticas, de igualdade aproximada. Esse pensamento é abordado no Fragmento póstumo 6 [58], discutido acima, no qual Nietzsche descreve o correlato sociopolítico da estratégia socrática de minimizar a discordância de nossos sentimentos:

- Assim é na vida social: se tudo deve proceder altruisticamente, então as oposições entre indivíduos devem ser reduzidas a um mínimo sublime: de modo que todas as tendências hostis e tensões através das quais o indivíduo mantém a si mesmo como indivíduo [durch welche das Individuum sich als Individuum erhält $]$ mal são percebidas, o que quer dizer: os indivíduos devem ser reduzidos à mais delicada tonalidade de individualidade! Assim, a igualdade predomina amplamente! Isso é eutanásia, completamente infecundo! [...] (Nachlass/FP 6 [58], KSA 9.207).

Se essas linhas descrevem a história dos animais de rebanho que vieram a dominar na modernidade, Nietzsche também sugere uma alternativa. Quando ele escreve: "as tensões e tendências hostis através das quais o indivíduo mantém a si mesmo como indivíduo", ele está conectando um forte antagonismo interior com um antagonismo exterior e interpessoal como sua condição. É através das relações de tensão e antagonismo com os outros que o antagonismo dos impulsos internos é contido de melhor forma, de modo que o dividuum pode atingir unidade ou manter a si mesmo como indivíduo com a tensão interior máxima requerida para a soberania. $\mathrm{O}$ nível ou a proporção a que se refere o máximo antagonismo interno consistente com a existência individual é determinado pelas relações de tensão entre indivíduos que são mais ou menos iguais em força, de modo que nenhum é subjugado ou absorvido pelos outros. E uma vez que a maximização do antagonismo interno compatível com a integridade individual é a condição para uma pluralidade de tipos humanos soberanos e fecundos, nós podemos dizer que a sociofisiologia de Nietzsche sugere uma política de igualdade, não no sentido de direitos

214 | Cad. Nietzsche, Guarulhos/Porto Seguro, v.37, n.1, p. 185-218, 2016. 
iguais universais que nos protegeriam do conflito ou da usurpação, mas uma política da rivalidade entre forças mais ou menos iguais que permitem a uma pluralidade de indivíduos serem dividua fecundos, ao mesmo tempo em que mantêm sua unidade como indivíduos e o exercício da soberania nas suas relações com os outros.

Aspectos desse ideal político podem ser compreendidos nos tipos de relações descritas por Nietzsche no seu modelo orgânico de soberania, como no tópico "1) como autorregulação", onde o antagonismo aparece na forma de "medo de toda interferência estrangeira" e "no ódio contra [gegen] os inimigos". Mas a autorregulação também acarreta o momento crucial da "moderação" [Maaßhalten] ou medida. Sobre os tópicos 2) e 3) - Abundante compensação [overcompensation] e assimilação - o antagonismo toma a forma de "cobiça", "apropriação", "ânsia de poder", "fazer os outros dependentes de si" e "comandar". Contudo, isso é equilibrado pela "benevolência" no tópico "4) secreção", e obedecendo ao tópico “5) Poder metabólico: veneração temporária, admiração, tornarse dependente, enquadrar-se [...] ser capaz de servir". Relações entre forças mais ou menos iguais são reguladas por dependências recíprocas, comando e obediência recíprocos, benevolência e ódio, entre tomar e dar.

Por fim, os textos sociofisiológicos nietzschianos de 1881 desenvolvem não apenas uma potente crítica ao conceito liberal de pessoa [personhood] e de suas pressuposições metafísicas; eles também formulam um conceito alternativo de pessoa [personhood] $\mathrm{e}$ com base nele sugerem um contra-conceito de agência soberana que liga a singularidade (ou diversidade) e a manutenção do máximo - mas ponderado - antagonismo interno através de um antagonismo externo - e também ponderado - com os outros. Contra a alegação socrática de que o conflito de impulsos que nos constitui só pode ser ponderado (moderado) pela eliminação (ou ao menos pela redução) do nosso antagonismo interior, Nietzsche sugere que nosso antagonismo interior 
Siemens, H.

pode ser contido através de relações externas de um antagonismo ponderado com outros que têm forças aproximadamente iguais às nossas. No lugar do ideal socrático de paz interior ou harmonia pela eliminação do conflito, os textos de Nietzsche pontuam a possibilidade de transformar o conflito desmedido e destrutivo - a destruição mútua de impulsos em competição, e com sua destruição a destruição do indivíduo que eles habitam - em um conflito ponderado e fecundo. Quais condições institucionais são necessárias para manter o conflito ponderado e fecundo entre seres soberanos, das quais isso certamente depende, é uma questão que permanece em aberto.

\begin{abstract}
This essay examines Nietzsche's thought on the social and historical sources of the self as a counter-argument against the liberal concept of the individual. Nietzsche, it is argued, offers a powerful critique of the asocial, antecedently individuated concept of personhood, to which the liberal notion of freedom (the right to choose one's concept of the good) is attached, but also an alternative counter-concept of personhood and sovereignty. On the critical side are arguments to the effect that the individual or person is inseparable from its ends or values, which in turn are socially constituted, and that our capacities as individuals, especially for sovereign agency, are the product of a long social history and pre-history. On the positive side is the constructive counter-claim that the maintenance and cultivation of our capacities for productive, autonomous agency is dependent on relations of measured antagonism both between and within us as individuals, or rather: as dividua. These arguments are reconstructed along four main lines of thought: on the social origins and character of (self-) consciousness ( $§ \mathrm{I})$; on the (pre-)history and social constitution of our capacities as sovereign individuals (§ II); on the social origins of moral phenomena, understood as internalisations of communal norms (§ III); and Nietzsche's physiological destruction of the substantial moral subject, coupled with the physiological reconstruction of the subject as dividuum (§ IV).
\end{abstract}

Keywords: sovereignty - socio-physiology - nature - moral

$216 \mid$ Cad. Nietzsche, Guarulhos/Porto Seguro, v.37, n.1, p. 185-218, 2016. 
Nietzsche e a sociofisiologia do eu

\section{Referências bibliográficas}

ARENDT, Hannah. "Philosophy and Politics". In. Social Research 57/1 (Spring), 1990, p. 73-103.

AYDIN, Ciano. Zijn en Worden. Nietzsches omduiding van het substantiebegrip, Maastricht: Shaker, 2003.

GERHARDT, Volker. "Selbstbegründung. Nietzsche's Moral der Individualität". In. Nietzsche-Studien, 21, 1992, p. 28-49.

HOBBES, Thomas. Leviathan. Oxford: Oxford University Press, 1998.

MEYER, Katrin. Ästhetik der Historie: Fr. Nietzsches "Vom Nutzen und Nachteil der Historie für das Leben”, Epistemata Würzburger Wissenschaftliche Schriften, Reihe Philosophie Bd. 238. Würzburg: Königshausen \& Neumann, 1998.

MÜLLER-LAUTER, Wolfgang."Der Organismus als innerer Kampf. Der Einfluss von Wilhelm Roux auf Fr. Nietzsche”. In. Nietzsche-Studien 7, 1978, p. 189 -223 .

"Der Organismus als innerer Kampf. Der Einfluss von Wilhelm Roux auf Fr. Nietzsche". In. Über Werden und Wille zur Macht, Nietzsche-Interpretationen I Berlin/New York: Walter de Gruyter, 1999, p. 97-140.

MULHALL, Stephen \& SWIFT, Adam. Liberals and Communitarians. Oxford: Blackwell, 1992.

. "Rawls and Communitarianism". In. FREEMAN, S. (Ed.). The Cambridge Companion to Rawls. Cambridge: CUP, 2003, p. 460-487.

MOUFFE, Chantal. "Democracy, Power and the "Political"”. In. BENHABIB, Seyla (Ed.).Democracy and Difference: Contesting the boundaries of the political. Princeton: Princeton University Press, 1996, p. 245-256.

NIETZSCHE, F. Sämtliche Werke Kritische Studienausgabe. In. 15 Bänden, herausgegeben von G. Colli \& M Montinari. B erlIn. Walter de Gruyter, 1967-77.

. Além do bem e do mal. Trad. De Paulo César de Souza. São Paulo: Cia das Letras, 1992.

OWEN, David. Nietzsche, Politics \& Modernity. London: Sage, 1995.

Cad. Nietzsche, Guarulhos/Porto Seguro, v.37, n.1, p. 185-218, 2016. 
Siemens, H.

PLATÃO. Górgias. Trad. de Carlos Alberto Nunes. Ed. Universitária do Pará, 2002.

RAWLS, John. A Theory of Justice. Oxford: OUP, 1971.

SIEMENS, H.W. "Nietzsche contra Liberalism on Freedom". In. ANSELLPEARSON, Keith (Ed.). A Companion to Nietzsche. Oxford and Malden MA: Basil Blackwell, 2006, p. 437-454.

. "Nietzsche and the Temporality of self-Legislation". In. DRIES, Manuel. Nietzsche on Time and History, (Ed.). Berlin /NY: de Gruyter, 2008, p. 191-210.

. "Nietzsche's Critique of Democracy". In. Journal of Nietzsche Studies 38, Fall, 2009, p. 20-37.

. "(Self-)legislation, Life and Love in Nietzsche's Philosophy". In : Neue Beiträge zu Nietzsches Moral-, Politik- und Kulturphilosophie. Ed. Isabelle Wienand (Ed.). Fribourg: Press Academic Fribourg, 2009, p. 67-90.

Empfindung In. Nietzsche-Wörterbuch (Nietzsche Online (NO) (2011). De Gruyter (Ed.). Berlin, Boston: De Gruyter. DOI: 10.1515/NO_W017186_0080), 2011.

Artigo recebido para publicação em 16/10/2015.

Artigo aceito para publicação em 06/12/2015.

218 Cad. Nietzsche, Guarulhos/Porto Seguro, v.37, n.1, p. 185-218, 2016. 